\title{
Período de suplementação de ractopamina em dietas para suínos machos castrados em terminação
}

\author{
Lenght of ractopamine supplementation in diets for finishing barrows
}

\author{
Bruna Ferreira de Oliveira ${ }^{\mathrm{I}}$ Charles Kiefer $^{\mathrm{I}}$ Tânia Mara Baptista dos Santos ${ }^{\mathrm{II}}$ \\ Elis Regina de Moraes Garcia ${ }^{\text {II }}$ Danilo Alves Marçal ${ }^{\mathrm{I}}$ Rodrigo Caetano de Abreu \\ Gabriela Puhl Rodrigues ${ }^{\mathrm{I}}$
}

\section{RESUMO}

\begin{abstract}
O objetivo do estudo foi determinar o período ideal de suplementação de 20ppm de ractopamina nas dietas de suínos machos castrados em terminação. Foram utilizados

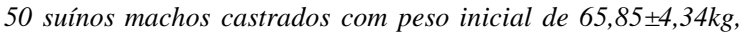
distribuídos em delineamento de blocos ao acaso, com seis tratamentos $(0,7,14,21,28$ e 35 dias de suplementação de ractopamina pré-abate), sendo quatro repetições para os tratamentos $0,7,14,21$ e 28 dias e cinco repetições para o tratamento com suplementação por 35 dias. A unidade experimental foi composta por dois animais. A conversão alimentar melhorou $(P<0,05)$ e o peso de carcaça quente, quantidade de carne magra e o indice de bonificação aumentaram linearmente $(P<0,05)$ de acordo com o aumento do período de suplementação de ractopamina. O retorno econômico para quantidade de carne magra produzida por animal aumentou linearmente até sete dias de suplementação, período a partir do qual se manteve no platô $(P<0,05)$. A suplementação de 20ppm de ractopamina na dieta dos suínos machos castrados em terminação, durante o período de 35 dias, melhora a conversão alimentar, aumenta o peso de carcaça quente, a quantidade de carne magra e o indice de bonificação. A suplementação de 20ppm de ractopamina na dieta de suínos em terminação resulta em retorno econômico para quantidade de carne magra produzida por animal, independentemente da duração da suplementação.
\end{abstract}

Palavras-chave: aditivo, $\beta$ adrenérgico, características de carcaça, custo de suplementação.

\section{ABSTRACT}

The study was conducted to determine the optimal period of supplementation of 20ppm of ractopamine in diets of finishing barrows. Fifty pigs, with initial weight of $65.85 \pm 4.34 \mathrm{~kg}$ were used. The pigs were distributed in randomized blocks design of six treatments (supplementation of ractopamine for $0,7,14,21,28$ and 35 days pre-slaughter), with four replications for treatments $0,7,14,21$ and 28 days and five replicates for the treatment supplemented by 35 days. Each experimental unit consisted of two animals. The feed conversion improved $(P<0.05)$ and the hot carcass weight, the amount of lean meat and the index of carcasses increased linearly $(P<0.05)$ with increasing period of ractopamine supplementation. The economic return for the amount of lean meat produced per animal improved linearly until the period of seven days of supplementation with ractopamine, from which remained at a plateau $(P<0.05)$. Supplementation of 20ppm of ractopamine in the diet of finishing barrows during the 35 days improved feed conversion, increases the hot carcass weight, the amount of lean meat and the index of carcasses. The supplementation of 20ppm ractopamine in the diet of finishing barrows results in economic return for the amount of lean meat produced per animal regardless of the length of supplementation.

Keywords: additive, $\beta$ adrenergic, carcass characteristics, cost of supplementation.

\section{INTRODUÇÃO}

A ractopamina é um aditivo oneroso e por isso pesquisadores têm estudado protocolos que potencializem sua ação com aumento mínimo do custo de produção. Além da genética, nível de lisina e proteína, programa alimentar, o nível de inclusão de ractopamina e o período de suplementação podem influenciar na

'Universidade Federal de Mato Grosso do Sul (UFMS), 79074-460, Campo Grande, MS, Brasil. E-mail: charles.kiefer@ufms.br. *Autor para correspondência.

"Universidade Estadual de Mato Grosso do Sul (UEMS), Aquidauana, MS, Brasil. 
eficiência do aditivo (SCHINCKEL et al., 2003). A resposta à suplementação de ractopamina pode ser alterada pela duração do fornecimento (HERR et al., 2000), uma vez que é possível que os suínos com alta deposição de músculo apresentem resposta com menor tempo de suplementação (SCHINCKEL et al., 2002).

A máxima resposta da ractopamina tem sido obtida entre três (WILLIAMS et al., 1994) a cinco semanas (ARMSTRONG et al., 2004) de suplementação. Porém, na prática, a ractopamina tem sido suplementada na dieta dos suínos em períodos inferiores a quatro semanas, devido ao seu custo elevado. Além disso, após 28 dias de suplementação, pode ocorrer redução lenta das respostas em função do fenômeno chamado down-regulation, ou dessensibilização dos receptores ß-adrenérgicos (MOODY et al., 2000). Portanto, realizou-se este estudo com o objetivo de determinar o período ideal da suplementação de $20 \mathrm{ppm}$ de ractopamina em dietas para suínos machos castrados em terminação sobre o desempenho, características quantitativas de carcaça e retorno econômico.

\section{MATERIAL E MÉTODOS}

$\mathrm{O}$ experimento foi conduzido no setor de suinocultura da Faculdade de Medicina Veterinária e Zootecnia (FAMEZ/UFMS), em Terenos/MS. Foram utilizados 50 suínos, machos castrados, Pietran/Duroc $x$ Large White/Landrace, com $65,85 \pm 4,34 \mathrm{~kg}$, distribuídos em delineamento de blocos ao acaso, composto por seis períodos de suplementação $(0,7$, 14, 21, 28 e 35 dias de suplementação com 20ppm de ractopamina pré-abate), com quatro repetições para os tratamentos $0,7,14,21$ e 28 dias e cinco repetições para o tratamento com suplementação por 35 dias. Aunidade experimental foi composta por dois animais. $\mathrm{O}$ critério de bloqueamento utilizado foi o peso inicial dos animais. O período experimental teve duração de 35 dias.

As dietas experimentais (Tabela 1) foram formuladas seguindo-se o conceito de proteína ideal proposto por ROSTAGNO et al. (2011), com reajuste de $20 \%$ para o nível dos aminoácidos das dietas, considerando o aumento da exigência proteica dos animais, devido à suplementação de ractopamina (XIAO et al., 1999). Durante o período experimental, a ração e a água foram fornecidas à vontade aos animais. Foram coletados diariamente os resíduos de ração do chão, que foram somados às sobras do comedouro para, ao final do período experimental, determinar o consumo de ração diário. Os animais foram pesados no início e final do experimento, visando à obtenção de dados relativos a ganho de peso e conversão alimentar.
Tabela 1 - Composições e valores calculados das dietas experimentais.

\begin{tabular}{|c|c|c|}
\hline \multirow{2}{*}{ Ingredientes } & \multicolumn{2}{|c|}{-----Ractopamina, ppm----- } \\
\hline & 0 & 20 \\
\hline Milho, $\mathrm{kg}$ & 53,796 & 53,796 \\
\hline Soja farelo $45 \%, \mathrm{~kg}$ & 21,325 & 21,325 \\
\hline Milheto, kg & 20,000 & 20,000 \\
\hline Óleo de soja, kg & 1,792 & 1,792 \\
\hline Fosfato bicálcico, kg & 0,815 & 0,815 \\
\hline Calcário calcítico, $\mathrm{kg}$ & 0,629 & 0,629 \\
\hline Sal comum, $\mathrm{kg}$ & 0,100 & 0,100 \\
\hline Suplemento vitamínico, $\mathrm{kg}^{1}$ & 0,400 & 0,400 \\
\hline Suplemento mineral, $\mathrm{kg}^{2}$ & 0,360 & 0,360 \\
\hline L-Lisina $\mathrm{HCl}, \mathrm{kg}$ & 0,413 & 0,413 \\
\hline L-Treonina, $\mathrm{kg}$ & 0,144 & 0,144 \\
\hline DL-Metionina, $\mathrm{kg}$ & 0,117 & 0,117 \\
\hline L-Triptofano, $\mathrm{kg}$ & 0,009 & 0,009 \\
\hline Inerte (caulim), $\mathrm{kg}$ & 0,100 & 0,000 \\
\hline Ractopamina, $\mathrm{kg}$ & 0,000 & 0,100 \\
\hline \multicolumn{3}{|l|}{ Composição calculada* } \\
\hline Proteína bruta, $\%$ & 16,86 & 16,86 \\
\hline Energia metabolizável, $\mathrm{kcal} \mathrm{kg}^{-1}$ & 3.230 & 3.230 \\
\hline Energia líquida, $\mathrm{kcal} \mathrm{kg}^{-1}$ & 2.447 & 2.447 \\
\hline Lisina total, $\%$ & 1,109 & 1,109 \\
\hline Lisina digestível, \% & 1,016 & 1,016 \\
\hline Metionina+cistina digestíveis, $\%$ & 0,610 & 0,610 \\
\hline Treonina digestível, \% & 0,681 & 0,681 \\
\hline Triptofano digestível, \% & 0,183 & 0,183 \\
\hline Valina digestível, \% & 0,701 & 0,701 \\
\hline Cálcio, \% & 0,510 & 0,510 \\
\hline Fósforo disponível, \% & 0,250 & 0,250 \\
\hline Fósforo total, \% & 0,468 & 0,468 \\
\hline Sódio, \% & 0,160 & 0,160 \\
\hline
\end{tabular}

${ }^{1}$ Conteúdo por kg de produto: ferro, $100 \mathrm{~g}$; cobre, 10g; cobalto, $0,2 \mathrm{~g}$; manganês, $30 \mathrm{~g}$; zinco, $100 \mathrm{~g}$; iodo, $1,0 \mathrm{~g}$; selênio, $0,3 \mathrm{~g}$; excipiente q.s.p., $1000 \mathrm{~g}$.

${ }^{2}$ Conteúdo por $\mathrm{kg}$ de produto: Vitamina A, 6.000.000UI; Vitamina D3, 1.000.000UI; Vitamina E, 12.000UI; Vitamina B1, 0,5g; Vitamina B2, 2,6g; Vitamina B6, 0,7g; ácido pantotênico, $10 \mathrm{~g}$; Vitamina $\mathrm{K} 3,1,5 \mathrm{~g}$; ácido nicotínico, 22g; Vitamina B12, 0,015g; ácido fólico, 0,2g; biotina, $0,05 \mathrm{~g}$; colina, $100 \mathrm{~g}$; excipiente q.s.p., $1000 \mathrm{~g}$.

*Composição calculada de acordo com recomendações propostas por Rostagno et al. (2011), acrescidas em $20 \%$ para os níveis de aminoácidos.

Ao término do período experimental, os animais permaneceram em jejum alimentar por 8 horas e posteriormente foram transportados para o frigorífico, onde foram pesados para determinar o rendimento de carcaça e abatidos. Foram realizados cortes na metade 
esquerda das carcaças para a exposição do músculo Longissimus dorsi e do toucinho, visando à determinação da profundidade do músculo e da espessura de toucinho, com o auxílio de paquímetro. Foram medidos os comprimentos das carcaças com auxílio de fita métrica. O percentual de carne magra na carcaça foi determinado através da equação proposta por BRIDI \& SILVA (2007): Rendimento de carne magra $(\%)=60$ - (espessura de toucinho $\times 0,58)+$ profundidade do músculo x 0,10 .

O índice de bonificação de carcaça foi calculado levando-se em consideração o peso da carcaça quente e o percentual de carne magra estimada na carcaça, de acordo com a equação sugerida por GUIDONI (2000): índice de bonificação $=23,6+0,286 \mathrm{x}$ peso de carcaça quente + percentual de carne na carcaça.

Para os cálculos de consumo de ractopamina, custo do consumo da ractopamina, retorno econômico para o ganho por animal e retorno econômico para a quantidade de carne magra por animal, foram realizadas as respectivas fórmulas: consumo de ractopamina, $\mathrm{g}=$ quantidade de ração consumida no período de suplementação, $\mathrm{kg}$ x percentual de ractopamina na dieta; custo da ractopamina consumida por animal, $\mathrm{R} \$=$ preço da ractopamina, $\mathrm{R} \$ \mathrm{~kg}^{-1} \mathrm{x}$ consumo de ractopamina no período, $\mathrm{kg}$. Retorno econômico para o ganho/animal, $\mathrm{R} \$=[$ (ganho de peso diário dos animais suplementados com ractopamina, $\mathrm{kg}$ - ganho de peso diário do grupo controle, $\mathrm{kg}$ ) x (período de suplementação, dias)] x (preço do suíno vivo, $\mathrm{R} \$ \mathrm{~kg}^{-1}$ ) - (custo da ractopamina consumida por animal, $\mathrm{R} \$$ ). Retorno econômico para a quantidade de carne magra, $\mathrm{R} \$=$ [(quantidade de carne magra dos animais suplementados com ractopamina, $\mathrm{kg}$ - quantidade de carne magra dos animais do grupo controle, $\mathrm{kg}$ ) x (preço da carne magra, $\mathrm{R} \$ \mathrm{~kg}^{-1}$ ) - (custo da ractopamina consumida por animal, $\mathrm{R} \$$ ). O preço estimado da ractopamina durante o período experimental foi de $R \$ 87,00 \mathrm{~kg}^{-1}$. O preço do suíno vivo e da carne magra foram de $\mathrm{R} \$ 2,70 \mathrm{~kg}^{-1}$ e $\mathrm{R} \$ 4,00 \mathrm{~kg}^{-1}$, respectivamente.

As variáveis analisadas de desempenho zootécnicos foram (ganho de peso, conversão alimentar, consumo de ração, consumo de lisina, proteína, energia metabolizável e de ractopamina), das características de carcaça (peso, rendimento, comprimento de carcaça, espessura de toucinho, percentual, quantidade de carne magra e profundidade de músculo) e análise econômica (custo da ractopamina consumida, retorno por ganho/ animal, retorno de quantidade de carne magra/animal e índice de bonificação). Os dados foram submetidos à análise de variância pelo procedimento GLM do programa estatístico SAS, sendo os graus de liberdade para o período de suplementação de ractopamina desdobrados em polinômios ortogonais e as estimativas do período de duração determinadas por meio de análises de regressão, ao nível de 5\% de probabilidade.

\section{RESULTADOS E DISCUSSÃO}

A inclusão de ractopamina na dieta não influenciou $(\mathrm{P}>0,05)$ no consumo de ração diário, no ganho de peso diário e no peso final dos animais (Tabela 2). $\mathrm{O}$ resultado obtido para o consumo de ração na presente pesquisa corrobora as observações de vários pesquisadores (MARINHO et al., 2007; MORAES et al., 2010; SANCHES et al., 2010a,b; SILVA et al., 2011) que avaliaram a suplementação de ractopamina na dieta de suínos. Uma vez que não foi constatada alteração para o consumo de ração no presente estudo, os consumos de proteína bruta, lisina digestível e energia metabolizável também não foram influenciados $(\mathrm{P}>0,05)$ pela duração da suplementação de ractopamina na dieta.

Por outro lado, o aumento do tempo de inclusão de ractopamina na dieta proporcionou melhora linear $(\mathrm{P}<0,05)$ da conversão alimentar, conforme a equação: $\hat{Y}=3,08461-0,01144 x, R^{2}=0,72$. De modo similar, ARMSTRONG et al. (2004), ao avaliarem níveis de 0, 5, 10 e 20ppm de ractopamina em períodos de 6, 13, 20, 27, 34 dias de suplementação, verificaram que a conversão alimentar melhorou durante todo o período experimental com a suplementação de $20 \mathrm{ppm}$ de ractopamina.

A partir dos resultados observados no presente estudo, pode-se inferir que a suplementação de 20ppm de ractopamina durante 35 dias possibilitou melhora de $11,5 \%$ sobre a conversão alimentar em relação ao grupo controle. Essa resposta também foi constatada por SILVA et al. (2011) com a suplementação de 20ppm de ractopamina, durante 35 dias, para leitoas sob temperatura elevada, em que a conversão alimentar foi melhorada em 19,8\%, comparada ao grupo controle. De modo similar, MIMBS et al. (2005) avaliando a suplementação de 10ppm de ractopamina aos 7, 14, 21 e 28 dias verificaram melhora da eficiência de utilização dos nutrientes da dieta com a suplementação por $21 \mathrm{e}$ 28 dias. Também CARR et al. (2005), ao avaliarem a suplementação de 10ppm de ractopamina, observaram que os suínos suplementados durante 14 e 28 dias apresentaram melhora na eficiência alimentar em relação ao grupo não suplementado.

Os efeitos positivos observados sobre a conversão alimentar, no presente estudo, podem ser explicados pela melhora da eficiência de utilização dos nutrientes das dietas suplementadas com ractopamina. Isso se deve ao efeito desse aditivo sobre o aumento da síntese proteica e bloqueio parcial da lipogênese 
Tabela 2 - Desempenho de suínos machos castrados em terminação, suplementados com ractopamina durante $0,7,14,21,28$ e 35 dias.

\begin{tabular}{|c|c|c|c|c|c|c|c|c|}
\hline \multirow{2}{*}{ Variáveis } & \multicolumn{6}{|c|}{-Período de suplementação (dias)-- } & \multirow{2}{*}{$\begin{array}{c}\text { Valor } \\
\text { P }\end{array}$} & \multirow{2}{*}{$\mathrm{CV} \%$} \\
\hline & 0 & 7 & 14 & 21 & 28 & 35 & & \\
\hline Peso inicial, kg & 66,15 & 65,60 & 65,83 & 65,99 & 65,56 & 65,97 & 0,170 & 7,40 \\
\hline Peso final, $\mathrm{kg}$ & 94,54 & 94,40 & 96,49 & 97,28 & 98,37 & 97,88 & 0,173 & 5,25 \\
\hline Consumo de ração, $\mathrm{kg} \mathrm{dia}^{-1}$ & 2,51 & 2,42 & 2,66 & 2,47 & 2,45 & 2,53 & 0,957 & 11,52 \\
\hline Consumo de lisina, $\mathrm{g} \mathrm{dia}^{-1}$ & 25,45 & 24,56 & 27,01 & 25,07 & 24,88 & 25,72 & 0,959 & 11,51 \\
\hline Consumo de proteína, $\mathrm{kg} \mathrm{dia}^{-1}$ & 0,42 & 0,41 & 0,45 & 0,42 & 0,42 & 0,43 & 0,952 & 11,54 \\
\hline Consumo de energia metabolizável, $\mathrm{kcal} \mathrm{dia}^{-1}$ & 80,92 & 78,00 & 85,86 & 79,7 & 79,08 & 81,77 & 0,958 & 11,51 \\
\hline Ganho de peso, $\mathrm{g} \mathrm{dia}^{-1}$ & 810 & 823 & 878 & 900 & 938 & 914 & 0,066 & 12,59 \\
\hline Conversão alimentar* & 3,13 & 2,93 & 3,04 & 2,77 & 2,65 & 2,77 & 0,028 & 10,37 \\
\hline Consumo de ractopamina, $\mathrm{g}^{*}$ & 0,00 & 17,08 & 40,04 & 54,44 & 68,20 & 88,61 & 0,001 & 15,72 \\
\hline Custo da ractopamina consumida, $\mathrm{R} \$ *$ & 0,00 & 1,49 & 3,48 & 4,74 & 5,93 & 7,71 & 0,001 & 15,74 \\
\hline Retorno/ganho/animal, $\mathrm{R} \$$ & 0,00 & $-0,37$ & 2,66 & 3,51 & 6,02 & 1,97 & 0,487 & 50,14 \\
\hline
\end{tabular}

*Efeito linear $(\mathrm{P}<0,05)$.

(SCHINCKEL et al., 2003). Essas modificações metabólicas favorecem o desempenho dos suínos, uma vez que a deposição de proteína, por agregar mais moléculas de água em relação à deposição de lipídios na carcaça (HALAS et al., 2010), pode melhorar tanto o ganho de peso quanto a eficiência alimentar.

Em função do aumento do período de suplementação de ractopamina, constatou-se aumento linear $(\mathrm{P}<0,05)$ da quantidade de ractopamina consumida e do custo de ractopamina, conforme as equações:

$\hat{Y}=1,0865+2,4942 x, R^{2}=0,95 ; \hat{Y}=-0,6461+0,3608$, $\mathrm{R}^{2}=0,92$, respectivamente. No entanto, não foi constatado efeito $(\mathrm{P}>0,05)$ da duração da suplementação de ractopamina sobre o retorno financeiro para o ganho de peso por animal, considerando as despesas com o consumo de ractopamina e o ganho de peso diferencial proporcionados com as suplementações do aditivo.

Verificou-se efeito $(\mathrm{P}<0,05)$ da suplementação de ractopamina sobre o peso de carcaça quente, que aumentou linearmente de acordo com o aumento do período de suplementação (Tabela 3), conforme a equação: $\hat{Y}=70,22789+0,14308 x, R^{2}=0,86$. Aumento linear para o peso de carcaça quente também foi constatado em estudo realizado por ARMSTRONG et al. (2004), quando suplementaram 20ppm de ractopamina durante cinco semanas. Em contrapartida, MOURA et al. (2011) e SILVA et al. (2011), ao pesquisarem a suplementação de $20 \mathrm{ppm}$ de ractopamina, para suínos em terminação, não observaram efeitos para essa variável.

Não foi constatado efeito $(\mathrm{P}>0,05)$ da duração da suplementação de ractopamina sobre o rendimento de carcaça dos suínos. Contudo, outros estudos realizados por CARR et al. (2005) e CANTARELLI et al. (2009) indicam que a ractopamina pode influenciar positivamente no rendimento de carcaça.

Apesar de serem verificados, no presente estudo, menores valores de espessura de toucinho nos grupos suplementados com ractopamina durante $28 \mathrm{e}$ 35 dias, nos quais houve redução de 12,90 e 12,17\%, respectivamente, a diferença não foi significativa $(\mathrm{P}>0,05)$. Esse mesmo resultado foi verificado por ARMOSTRONG et al. (2004) e MARINHO et al. (2007). Por outro lado, CANTARELLI et al. (2009) evidenciaram efeito da suplementação de $5 \mathrm{ppm}$ de ractopamina na dieta, durante 28 dias, sobre a redução da espessura de toucinho. Essas diferenças de resultado podem estar associadas às diferentes linhagens genéticas utilizadas nos diferentes experimentos.

A profundidade de músculo, o percentual de carne magra e o comprimento de carcaça não foram influenciados $(\mathrm{P}>0,05)$ pelos períodos de suplementação de ractopamina. Constatou-se efeito $(\mathrm{P}<0,05)$ da suplementação de ractopamina sobre a quantidade de carne magra e o índice de bonificação das carcaças, que aumentaram linearmente de acordo com o aumento do período de suplementação, conforme as equações: $\hat{Y}=42,34453+0,11344 x, R^{2}=0,82$ e $\hat{Y}=104,02897+0,07623 x, R^{2}=0,72$. De acordo com os resultados obtidos, os suínos suplementados com ractopamina durante 35 dias apresentaram melhora de 10,57 e $2,59 \%$ para a quantidade de carne magra e o índice de bonificação, respectivamente, quando comparados àqueles não suplementados. 
Tabela 3 - Características de carcaça de suínos machos castrados em terminação, suplementados com ractopamina durante 0, 7, 14, 21, 28 e 35 dias.

\begin{tabular}{|c|c|c|c|c|c|c|c|c|}
\hline \multirow{2}{*}{ Variáveis } & \multicolumn{6}{|c|}{ - } & \multirow{2}{*}{$\begin{array}{c}\text { Valor } \\
\text { P }\end{array}$} & \multirow{2}{*}{$\mathrm{CV} \%$} \\
\hline & 0 & 7 & 14 & 21 & 28 & 35 & & \\
\hline Peso da carcaça quente, $\mathrm{kg}^{*}$ & 69,35 & 72,30 & 71,85 & 73,53 & 74,90 & 74,62 & 0,006 & 3,91 \\
\hline Rendimento de carcaça quente, $\%$ & 79,16 & 80,11 & 79,53 & 80,49 & 79,86 & 80,30 & 0,158 & 1,26 \\
\hline Espessura de toucinho, $\mathrm{mm}$ & 8,75 & 9,33 & 9,75 & 8,00 & 7,75 & 7,80 & 0,514 & 32,88 \\
\hline Profundidade de músculo, mm & 54,75 & 57,50 & 58,00 & 56,33 & 63,50 & 61,00 & 0,127 & 12,00 \\
\hline Comprimento de carcaça, $\mathrm{cm}$ & 90,00 & 89,75 & 89,50 & 88,50 & 89,75 & 88,20 & 0,230 & 2,36 \\
\hline Carne magra na carcaça, $\%$ & 60,40 & 60,49 & 60,15 & 60,69 & 61,86 & 61,58 & 0,209 & 2,73 \\
\hline Quantidade de carne magra, $\mathrm{kg}^{*}$ & 41,89 & 44,13 & 43,18 & 44,61 & 46,32 & 45,94 & 0,001 & 3,96 \\
\hline Retorno/carne magra/animal, $\mathrm{R} \$ *$ & 0,00 & 7,47 & 1,68 & 6,14 & 11,78 & 8,49 & 0,044 & 68,34 \\
\hline Índice de bonificação* & 103,83 & 105,39 & 104,29 & 105,31 & 106,88 & 106,52 & 0,007 & 1,50 \\
\hline
\end{tabular}

*Efeito linear $(\mathrm{P}<0,05)$.

Provavelmente, esses resultados estão relacionados ao aumento linear observado para o peso de carcaça quente, de acordo com o aumento do período de suplementação de ractopamina.

Observou-se que, quando testada pelo modelo descontínuo linear response plateau, houve aumento linear $(\mathrm{P}<0,05)$ do retorno econômico para a quantidade de carne magra produzida por animal até o sétimo dia de suplementação, mantendo-se constante após o sétimo dia de suplementação. O resultado permite inferir que a suplementação de $20 \mathrm{ppm}$ de ractopamina na dieta dos suínos em terminação pode resultar em retorno econômico, devido ao aumento proporcionado sobre a quantidade de carne magra produzida por animal, independentemente da duração da suplementação.

\section{CONCLUSÃO}

A inclusão de 20ppm de ractopamina na dieta de suínos machos castrados em terminação, durante 35 dias, melhora a conversão alimentar, aumenta o peso de carcaça, a quantidade de carne magra e o índice de bonificação. A suplementação de 20ppm de ractopamina na dieta de suínos em terminação resulta em retorno econômico para quantidade de carne magra produzida por animal, independentemente da duração da suplementação.

\section{COMITÊ DE ÉTICA E BIOSSEGURANÇA}

Aprovado pela comissão de ética no uso de animais protocolo $n^{\circ} 425 / 2012$ - UFMS.

\section{REFERÊNCIAS}

ARMSTRONG, T.A. et al. The effect of dietary ractopamine concentration and duration of feeding on growth performance, carcass characteristics, and meat quality of finishing pigs. Journal of Animal Science, v.82, p.3245-3253, 2004. Disponível em: <http://www.animal-science.org/content/82/11/ 3245.full.pdf+html>. Acesso em: 05 out. 2011.

BRIDI, A.M.; SILVA, C.A. Métodos de avaliação de carcaça e da carne suína. Londrina: Midiograf, 2007. 97p.

CANTARELLI, V.S. et al. Características da carcaça e viabilidade econômica do uso de cloridrato de ractopamina para suínos em terminação com alimentação à vontade ou restrita. Ciência Rural, v.39, p.844-851, 2009. Disponível em: <http:/ /www.scielo.br/pdf/cr/v39n3/a32v39n3.pdf>. Acesso em: 12 out. 2011. doi: 10.1590/S0103-84782009000300032.

CARR, S.N. et al. Effects of different cereal grains and ractopamine hydrochloride on performance, carcass characteristics, and fat quality in late-finishing pigs. Journal of Animal Science, v.83, p.223-230, 2005. Disponível em: <http://www.animal-science.org/content/83/1/ 223.full.pdf+html>. Acesso em: 15 out. 2011.

GUIDONI, A.L. Melhoria de processos para a tipificação e valorização de carcaças suínas no Brasil. In: CONFERÊNCIA INTERNACIONAL VIRTUAL SOBRE QUALIDADE DE CARNE SUÍNA, 2000, Concórdia, SC. Anais... Concórdia: EMBRAPA CNPSA, 2000. p.14.

HALAS, V. et al. Efficiency of fat deposition from non-starch polysaccharides, starch and unsaturated fat in pigs. British Journal of Nutrition, v.103, p.123-133, 2010. Disponível em: <http://journals.cambridge.org/action/displayAbstract? fromPage $=$ online \&aid=6889092 $>$. Acesso em: 05 ago. 2012. doi: $10.1017 / \mathrm{S} 0007114509991449$.

HERR, C.T. et al. Effect of nutritional level while feeding Paylean $^{\mathrm{TM}}$ to late-finishing swine. Swine Day, p.89-95, 2000. 
Disponível em: <http://www.ansc.purdue.edu/swine/swineday/ sday00/16.pdf>. Acesso em: 10 out. 2011.

MARINHO, P.C. et al. Efeito da ractopamina e de métodos de formulação sobre o desempenho e as características de carcaça de suínos machos castrados em terminação. Revista Brasileira de Zootecnia, v.36, p.1061-1068, 2007. Disponível em: 〈http://www.scielo.br/pdf/rbz/v36n4s0/11.pdf>. Acesso em: 12 out. 2010. doi: 10.1590/S151635982007000500011 .

MIMBS, K.J. et al. Effects of ractopamine on performance and composition of pigs phenotypically sorted into fat and lean groups. Journal of Animal Science, v.83, p.13611369, 2005. Disponível em: <http://jas.fass.org/content/83/6/ 1361.full.pdf+html>. Acesso em: 12 out. 2011.

MOODY, D.E. et al. Phenethanolamine repartitioning agents. In: MELLO, J.P.F.D. Farm animal metabolism and nutrition. New York: CAB, 2000. p.65-95.

MORAES, E. et al. Ractopamina em dietas para suínos machos imunocastrados, castrados e fêmeas. Ciência Rural, v.40, p.409-414, 2010. Disponível em: <http://www.scielo.br/pdf/ cr/v40n2/a473cr1765.pdf >. Acesso em: 12 out. 2011. doi: 10.1590/S0103-84782010000200024.

MOURA, S.M. et al. Energia líquida e ractopamina para leitoas em terminação sob altas temperaturas ambientais. Ciência Rural, v.41, p.888-894, 2011. Disponível em: <http:// www.scielo.br/pdf/cr/v41n5/a964cr4196.pdf >. Acesso em: 12 out. 2011. doi: 10.1590/S0103-84782011000500025.

ROSTAGNO, H.S. et al. Tabelas brasileiras para aves e suínos: composição de alimentos e exigências nutricionais. 3.ed. Viçosa, MG: UFV, 2011. 252p.

SANCHES, J.F. et al. Níveis de ractopamina para suínos machos castrados em terminação e mantidos sob conforto térmico.

Ciência Rural, v.40, p.403-408, 2010a. Disponível em: 〈http://www.scielo.br/pdf/cr/v40n2/a441cr1445.pdf〉. Acesso em: 12 out. 2011. doi: 10.1590/S0103-84782009005000257.

SANCHES, J.F. et al. Níveis de ractopamina para suínos machos castrados em terminação mantidos sob estresse por calor. Revista Brasileira de Zootecnia, v.39, p.1523-1529, 2010b. Disponível em: <http://www.scielo.br/pdf/rbz/v39n7/ a19v39n7.pdf $>$. Acesso em: 12 out. 2011. doi: 10.1590/S151635982010000700019 .

SCHINCKEL, A.P. et al. Variation in the response of multiple genetic populations of pigs to ractopamine. Journal of Animal Science, v.80, p.85-89, 2002. Disponível em: <http:// jas.fass.org/content/80/E-Suppl_2/E85.full.pdf >. Acesso em: 12 out. 2011.

SCHINCKEL, A.P. et al. Ractopamine treatment biases in the prediction of pork carcass composition. Journal of Animal Science, v.81, p.16-28, 2003. Disponível em: <http://jas.fass.org/ content/81/1/16.full.pdf+html>. Acesso em: 12 out. 2011.

SILVA, A.E. et al. Duração da suplementação de ractopamina em dietas para leitoas em terminação mantidas sob alta temperatura ambiente. Ciência Rural, v.41, p.337-342, 2011. Disponível em: 〈http://www.scielo.br/pdf/cr/v41n2/a851cr3476.pdf〉. Acesso em: 12 out. 2011. doi: 10.1590/S010384782011005000001

WILLIAMS, N.H. et al. The impact of ractopamine, energy intake, and dietary fat on finisher pig growth performance and carcass merit. Journal of Animal Science, v.72, p.31523162, 1994. Disponível em: <http://jas.fass.org/content/72/ 12/3152.full.pdf+html>. Acesso em: 12 out. 2011.

XIAO, R.J. et al. Effects of ractopamine at different dietary protein levels on growth performance and carcass characteristics in finishing pigs. Animal Feed Science and Technology, v.79, p.119-127, 1999. Disponível em: <http://www.sciencedirect.com/ science/article/pii/S037784019800282X>. Acesso em: 10 ago. 2012. doi: 10.1016/S0377-8401(98)00282-X. 